\title{
Prostatic Calculi: A Harbor for Infections, a Case Report and Review of Literature
}

\author{
Rafay Khan ${ }^{a}$, Waqas Jehangir ${ }^{a}$,, Shilpi Singh ${ }^{a}$, Shuvendu Sen ${ }^{a}$, Abdalla Yousif ${ }^{a}$
}

\begin{abstract}
Prostatic calculi can be common but are usually found incidentaly. In most cases, they are asymptomatic; however, they have been associated with various symptoms, some of which are well documented. We report a case of an 85-year-old male who initially presented with dyspnea but also a complaint of urinary retention, and was found to have prostalithiasis after transurethral resection of the prostate (TURP). The association of prostatic calculi, benign prostatic hypertrophy, and urinary tract infection has been reported but not well documented in the literature. Although they are discovered in patients with benign prostatic hypertrophy $(\mathrm{BPH})$ or those being evaluated with prostate cancer, no well etiology or other risk factors have been researched.
\end{abstract}

Keywords: Prostate; Calculi; Stone; Infection

\section{Introduction}

Prostatic calculi which are most often asymptomatic often coexist with prostatitis or benign prostatic hyperplasia in elderly men and can result in lower urinary tract symptoms [1]. A distinction needs to be made primarily noting that true prostatic calculi are different from urinary calculi which may present in a dilated prostatic urethra or pouch of the urethra [1]. However, it remains unclear the cause of stone formation and whether the source of infection is directly correlated or is an adverse outcome of the presence of the calculi. Furthermore, in patients with benign prostatic hyperplasia, further research needs to be emphasized in regards to whether such calculi can result in worsening of symptoms such as urinary retention, increased the risk of infection, and if there is an increased risk of kidney injury or hydronephrosis.

\section{Manuscript accepted for publication March 30, 2015}

aDepartment of Internal Medicine, Raritan Bay Medical Center, $530 \mathrm{New}$ Brunswick Ave., Perth Amboy, NJ 08861, USA

${ }^{b}$ Corresponding Author: Waqas Jehangir, Department of Internal Medicine, Raritan Bay Medical Center, 530 New Brunswick Avenue, Perth Amboy, NJ 08861, USA. Email: WJehangir@hotmail.com

doi: http://dx.doi.org/10.14740/wjnu208w

\section{Case Report}

An 85-year-old Caucasian male with a past medical history of hypertension, atrial fibrillation, and benign prostatic hypertrophy (BPH) presented to the emergency room with a complaint of shortness of breath and urinary retention. He stated that the shortness of breath has been progressively worsening over the course of 3 - 4 weeks but denied any chest pain. He expressed that he has been experiencing dysuria with increased difficulty urinating.

Lab data were obtained prior to admission and consisted of basic metabolic panel showing a sodium of $129 \mathrm{mmol} / \mathrm{L}$, potassium of $3.7 \mathrm{mmol} / \mathrm{L}$, chloride of $87 \mathrm{mmol} / \mathrm{L}$, bicarbonate of $34 \mathrm{mmol} / \mathrm{L}$, BUN of $10 \mathrm{mg} / \mathrm{dL}$, creatinine of $0.7 \mathrm{mg} / \mathrm{dL}$, and glucose of $118 \mathrm{mg} / \mathrm{dL}$. Other labs consisted of a white blood cell count of $6,300 / \mu \mathrm{L}$, hemoglobin of $7.9 \mathrm{~g} / \mathrm{dL}$, hematocrit of $26.8 \%$, and platelets of $258,000 / \mu \mathrm{L}$. Urine analysis showed large amount of blood, many white blood cells, and many red blood cells. Chest X-ray suggested congestive heart failure. The patient was admitted to telemetry and transfused two units of PRBCs, improving his hemoglobin to $9.4 \mathrm{~g} / \mathrm{dL}$ and hematocrit to $28.3 \%$. His shortness of breath improved post-transfusion and with the administration of intravenous lasix.

The patient continued to have urinary retention and renal ultrasound demonstrated bilateral renal cysts but no evidence

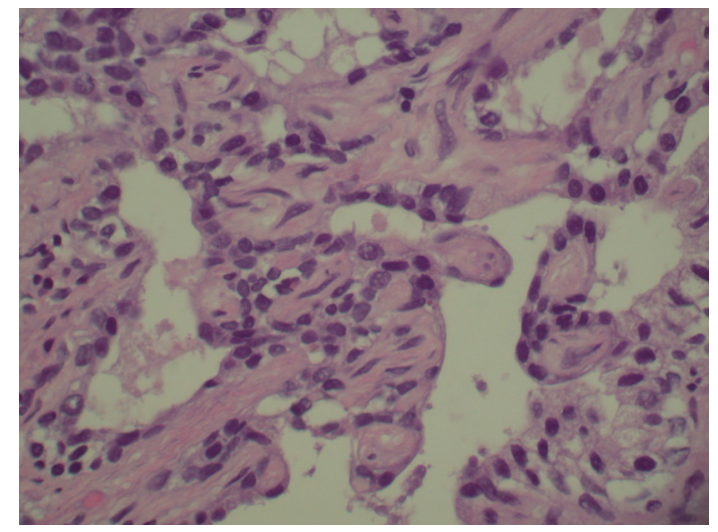

Figure 1. Benign prostatic hypertrophy with prostatolithiasis and focal chronic inflammation. 
of hydronephrosis. Urine cultures were positive for Enterococcus faecalis group D for which the patient was managed with vancomycin and cefazolin. Urology recommended prostate biopsy and transurethral resection of the prostate (TURP) due to his ongoing retention and elevated PSA of $21.1 \mathrm{ng} / \mathrm{mL}(0$ - $4 \mathrm{ng} / \mathrm{mL}$ ). Patient successfully underwent cystoscopy with TURP. Pathology of the prostate tissue was significant for $\mathrm{BPH}$ with prostalithiasis and focal chronic inflammation (Fig. 1). There was also some basal cell hyperplasia and squamous metaplasia along with mild chronic inflammation.

Patient tolerated the procedure well and was able to return home without any further complications after having a chronic indwelling catheter placed due to findings suggestive of neurogenic bladder.

\section{Discussion}

True prostatic stones are formed by the deposit of calcareous ingredients into the corpora amylacea, which is a small ovoid structure present within the actual alveoli of the prostate gland [1]. How these stones are formed is still a question up for debate. It has been reported however, that false stones may form from salts that are precipitated in the normal prostatic fluid which is composed of calcium and magnesium phosphates compared to true stones which are formed by inorganic salts [2]. These inorganic salts are composed of calcium phosphate and calcium carbonate which are converted into calculi within the corpora amylase [2]. There is a more specific form of classifications differentiating the types of prostatic calculi which include primary calculi, pure primary calculi, impure calculi, and secondary exogenous calculi. Endogenous calcifications can be formed by the precipitation of elements present in the prostatic secretions which can result from obstruction, inflammation, and chronic infection of the ducts. However, when the stones are exogenous, they are formed from constituents of the urine, as shown by crystallographic studies of prostatic calculi $[3,4]$.

It is difficult to diagnose the presence of prostatic calculi clinically without the use of further testing as it can be predicted with gallstones and kidney stones. There are no specific symptoms associated with prostatic calculi and some patients may even remain asymptomatic. As seen in this case report, most individuals diagnosed with such a condition are normally found incidentally and usually have symptoms secondary to other conditions such as BPH, chronic prostatitis, or even a urethral stricture. Some research has discussed a possible correlation with lower pain in the back, perineum, or penis; however, these symptoms can also present in patients with prostatic enlargement and urethral stricture [1]. In most cases, there is no hematuria which is different than that which was observed in the urinalysis of this case report. These findings as well may not be very specific.

Diagnosis of prostatic calculi is normally found incidentally. Some cases have been reported where they have been found on digital rectal examination, pelvic radiographs, transrectal ultrasound, and TURP procedures [1]. Asymptomatic patients discovered to have prostatic calculi do not require any further intervention. Cases such as that reported, have several options available for management of the symptoms. The main method of treatment includes TURP (as used in this patient), transurethral surgical removal with ultrasonic observation, or supra-pubic removal for those with large stones [5]. Lesser used methods include perineal prostatomy and total prostatectomy in cases where there are deep stones or multiple symptomatic stones present [1].

The question remains, whether and how prostatic calculi can result in an increased risk of urinary tract infection (UTI). Prostatic calculi result in inflammation by causing obstruction to the central prostatic ducts thus preventing urinary drainage and providing a nidus for bacteria to survive the host's defenses and antibiotics [6]. Bacterial colonizations within prostatic calculi can result in chronic prostatitis and recurrent UTIs although the patient may be on antibiotics, as they may remain hidden in the crevices of the prostatic calculi [7]. This demonstrates the point that prostatic calculi need to be taken into consideration when imaging results are insignificant and a patient with a history of BPH with recurrent UTIs is not responding to antibiotic treatment.

Song-Woo and affiliates were able to illustrate that prostatic calculi and urinary tract symptoms were closely related [8]. In their study, 1,527 individuals with UTIs were analyzed and consisted of a complete workup of 802 males who underwent evaluations consisting of transrectal ultrasound scans, voided bladder-3 specimen and international prostatic symptoms score (IPSS) [1, 8]. Using multivariate analyses along with univariate analysis predictive factors of lower urinary tract symptoms, IPSS, predisposing factors, as well as the presence of prostatic calculi, a correlation was made between the two conditions. They were able to conclude that prostatic calculi were associated with a more severe form of lower urinary tract symptoms not only because of the stone but also because the stones are associated with independent predisposing factors themselves such as old age and large prostate volume $[1,8]$. It was unknown whether the prostatic calculi thus were clinically significant or if they had the potential to cause the symptoms. It is difficult to conclude and properly diagnose prostatic calculi, but further research needs to address their presence and awareness especially in patients with predisposing factors that present with recurrent or unresolving UTIs.

\section{Conclusion}

Prostatic calculi can be associated with BPH and prostatis in elderly men. Many of these patients present with symptoms of UTI and dysuria, while others may remain asymptomatic. No significant development or research has been placed, however, if such calculi can worsen the severity of the BPH, affect the PSA level, or result in an increased urinary retention. Diagnostic imaging is not always successful in discovering their presence; however, these additional symptoms should take them into consideration if not already found incidentally.

\section{References}

1. Venyo A. Prostatic Calculi: A Review of the Literature. 
Webmed Central UROLOGY. 2012;3(6):WMC003463.

2. Sutor DJ, Wooley SE. The crystalline composition of prostatic calculi. Br J Urol. 1974;46(5):533-535.

3. Najoui M, Qarro A, Ammani A, Alami M. Giant prostatic calculi. Pan Afr Med J. 2013;14:69.

4. Torres Ramirez C, Aguilar Ruiz J, Zuluaga Gomez A, Espuela Orgaz R, Del Rio Samper S. A crystallographic study of prostatic calculi. J Urol. 1980;124(6):840-843.

5. Drach GW. Calculi of the prostate and seminal vesicles in Urinary lithiasis: etiology, diagnosis, and medical management. In: Walsh PC, Retik AB, Stamey TA, Vaughan Jr., ED editors. Campbell's Urology, 6th ed. Philadelphia, London,
Toronto, Montreal, Sydney, Tokyo: W. B. Saunders Company. Harcourt Brace Jovanovic Inc. 1992;3:2142-2144.

6. Blacklock N. Prostatitis. In: Whitfield HN, Hendry WF, Kirby RS, Duckett JW, eds. Textbook of Genitourinary Surgery, 2nd ed. London, United Kingdom: Blackwell Science, 1998:633-641.

7. Eykyn S, Bultitude MI, Mayo ME, Lloyd-Davies RW. Prostatic calculi as a source of recurrent bacteriuria in the male. Br J Urol. 1974;46(5):527-532.

8. Park SW, Nam JK, Lee SD, Chung MK. Are prostatic calculi independent predictive factors of lower urinary tract symptoms? Asian J Androl. 2010;12(2):221-226. 